\title{
METHODOLOGY TO TEST THE ELECTROMAGNETIC COMPATIBILITY OF A THREE PHASE INVERTER
}

\author{
Pallavi.N \\ M.Tech, EEE Department \\ BMS College of Engineering \\ Bengaluru, India
}

\author{
Dr. P. Meena \\ Professor and HOD, \\ EEE Department \\ BMS College of Engineering \\ Bengaluru, India
}

\begin{abstract}
This paper presents the methodology to determine the Electromagnetic Compatibility a threephase inverter. The intention is to carry out the conducted and radiated emission testing of a three-phase inverter as per the CISPR-25 international standard in both simulation and hardware testing environments. For 3 dimensional testing, D simulation is being carried out using ANSYS software. Simulation results on the test samples are seemingly conforming to the required standards when compared with that obtained through hardware.
\end{abstract}

Keywords- EMC-Electromagnetic compatibility Analysis, LISN, conducted emission, Radiated emission, CISPR-25, ANSYS, HFSS.

\section{INTRODUCTION}

Automotive industries adopted the Electronic control unit in the 1970s and since then it is playing a very significant role in transforming from being completely mechanical to being completely electronics dominant device. A rapid increase in the usage of mobile phones had pushed the carmanufacturers to the introduction of mobile connectivity within the car. This led to a better understanding of the technical issues ahead and the development of the testing procedure, and Electromagnetic compatibility (EMC) is one of them.

There is a need for determining the intersystem electromagnetic compatibility, and it should include predicting the expected level of interferences in specific operating conditions and developing a standard test method to meet the requirements of standard interference level [1].

Electromagnetic Interference is defined as unwanted electromagnetic energy that disturbs the right functioning of a device. All electronic devices generate some amount of radiation since the electricity flowing through its circuits and wires are never fully contained [2]. This energy from device "A", either propagated through the air as radiation or coupled into (or conducted along) I/O or cables of another device "B", could disrupt the operational balance in device $\mathrm{B}$, causing the device to malfunction sometimes in a hazardous way. This energy from device A interfering with operations of device $\mathrm{B}$ is noted as Electromagnetic Interference [3].
Electromagnetic compatibility is a property of equipment to have peaceful co-existence or not to have unacceptable impact and requires to have adequate immunity to the disturbance in that environment and path between source and receiver.

\section{METHODOLOGY OF TESTING}

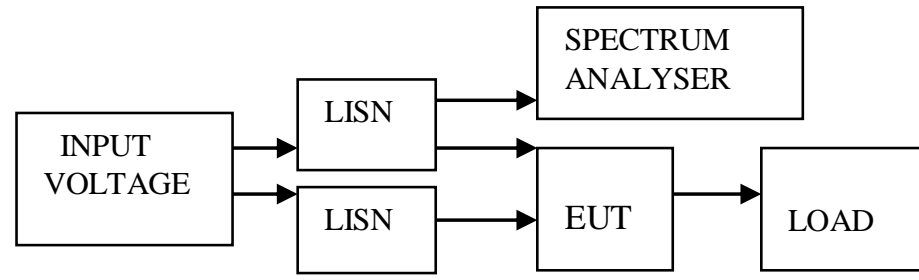

Fig 1. Block diagram for emission testing

EMC sample consists of Equipment which is a source of electromagnetic energy and requires emission to be limited, and the Equipment that receives electromagnetic energy. Conducted emission testing is carried out by modeling 3- D test set up with equipment under test and exported into circuit platform. Source is connected through Line impedance stabilization block (LISN) and EUT (Equipment Under Test) is terminated with load [4] .Spectrum analyzer is used to measure emission levels as shown in Fig 1.

\section{CISPR-25 STANDARD}

CISPR is one of the organizations that develop automotive standards in addressing EMC issues. [5] [6] CISPR-25 particularly deals with component or module level conducted and radiated emission limits [6].

Conducted emission level limits for $0.15-108 \mathrm{MHz}$ frequency range as per the CISPR-25 standard is given in Table I [7]. 
International Journal of Engineering Applied Sciences and Technology, 2020

Vol. 5, Issue 3, ISSN No. 2455-2143, Pages 446-450

Published Online July 2020 in IJEAST (http://www.ijeast.com)

TABLE I. CONDUCTION EMISSION LIMITS

\begin{tabular}{|c|c|c|c|c|c|}
\hline \multirow{2}{*}{$\begin{array}{l}\text { Frequency } \\
\text { in MHz }\end{array}$} & \multicolumn{5}{|c|}{ Levels in $\mathrm{dB}(\mu \mathrm{V})$} \\
\cline { 2 - 6 } & $\begin{array}{c}\text { Class } \\
1\end{array}$ & $\begin{array}{c}\text { Class } \\
2\end{array}$ & $\begin{array}{c}\text { Class } \\
3\end{array}$ & $\begin{array}{c}\text { Class } \\
4\end{array}$ & $\begin{array}{c}\text { Class } \\
5\end{array}$ \\
\hline $0.150-0.3$ & 110 & 100 & 90 & 80 & 70 \\
\hline $0.53-1.8$ & 86 & 78 & 70 & 62 & 54 \\
\hline $5.9-6.2$ & 77 & 71 & 65 & 59 & 53 \\
\hline $76-108$ & 62 & 56 & 50 & 44 & 38 \\
\hline $41-88$ & 58 & 52 & 46 & 40 & 34 \\
\hline
\end{tabular}

For radiated emission CISPR-25 recommends an antenna for a frequency range as shown in Table II [7].

\section{TABLE II . ANTENNA RECOMMENDATION}

\begin{tabular}{|c|c|}
\hline Frequency Range & Recommended antenna \\
\hline $150 \mathrm{kHz}-30 \mathrm{MHz}$ & $1 \mathrm{~m}$ Vertical monopole \\
\hline $30 \mathrm{MHz}-300 \mathrm{MHz}$ & Biconical \\
\hline $200 \mathrm{MHz}-1 \mathrm{GHz}$ & Log-periodic \\
\hline $30 \mathrm{MHz}-1 \mathrm{GHz}$ & Broadband(bicoe+log=bilog) \\
\hline $1 \mathrm{GHz}-2.5 \mathrm{GHz}$ & Horn or log-periodic \\
\hline
\end{tabular}

Radiated emission limits for the $0.15-245 \mathrm{MHz}$ frequency range is given in Table III [7].

\section{TABLE III. RADIATED EMISSION LIMITS}

\begin{tabular}{|c|c|c|c|c|c|}
\hline Frequency & \multicolumn{5}{|c|}{ Levels in $\mathrm{dB}(\mu \mathrm{V} / \mathrm{m})$} \\
\cline { 2 - 6 } in MHz & Class1 & Class2 & Class3 & Class4 & Class5 \\
\hline $0.150-0.3$ & 86 & 76 & 66 & 56 & 46 \\
\hline $0.53-1.8$ & 72 & 64 & 56 & 48 & 40 \\
\hline $5.9-6.2$ & 64 & 58 & 52 & 46 & 40 \\
\hline $76-108$ & 62 & 56 & 50 & 44 & 38 \\
\hline $41-88$ & 52 & 46 & 40 & 34 & 28 \\
\hline $174-230$ & 56 & 50 & 44 & 38 & 32 \\
\hline $171-245$ & 50 & 44 & 38 & 32 & 26 \\
\hline
\end{tabular}

The limits for both conducted and radiated emission is categorized into different classes. Higher the class more stringent is the limit.

\section{ANSYS SOFTWARE}

ANSYS is a powerful engineering simulation and 3-D design software. High-frequency simulation structure (HFSS) is one of the features in ANSYS software.

HFSS employs a computational method which is the use of a sub-domain function making the solution process independent of the device shape. It is called discretization of the device in the form of cell or element as shown in Fig 2.

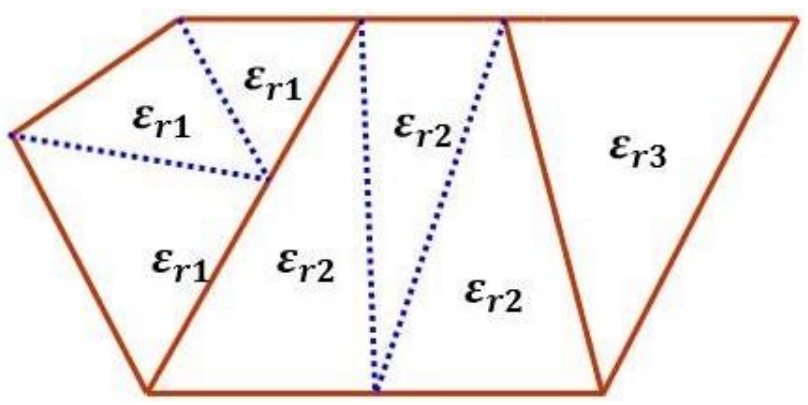

Fig.2 Discretization of the device into non- overlapping homogeneous cells

Whole device geometry is divided into one type of nonoverlapping. This discretization is carried out such that the dielectric is homogeneous in each cell discretization results in a system of a linear simultaneous equation which can be described by a matrix equation given by

$$
[A][x]=[b]
$$

Computational electromagnetics method involves efficiently solving the Maxwell equation to capture the interaction of fields (E-field and $\mathrm{H}$ - field) within the structure and also between structure and environment

$$
\begin{gathered}
\nabla \times=-j \omega B-M \\
\nabla \times=J+j \omega D \\
\nabla \cdot D=\rho \\
\nabla \cdot B=0
\end{gathered}
$$

Ansys solves the structure using 3D solver which employs discretization process and is governed by the Maxwell equation as shown in (2) to (5) and gives structure with RLGC parasitic as output. This structure is brought into circuit platform to carry out transient simulation to measure the noises.

\section{SIMULATION OF THE TESTS}

EMC simulation tool primarily solves for $\mathrm{E}$ and $\mathrm{H}$ field and extracts structure parasitic. Parasitics in high frequency is represented in terms of S-parameters. 
Then circuit tool feature in ANSYS is used to combine with source and load to observe the noise. Table IV gives the specification of three phase inverter.

TABLE IV. SPECIFICATIONS

\begin{tabular}{|c|c|}
\hline Input voltage & $350 \mathrm{~V}$ \\
\hline Frequency & $100 \mathrm{kHz}$ \\
\hline Output Voltage & $98 \mathrm{~V}$ \\
\hline Load parameter & $\mathrm{R}=100 \mathrm{~m} \Omega, \mathrm{L}=200 \mu \mathrm{H}$ \\
\hline
\end{tabular}

\section{Conducted emission setup}

Conducted emission 3-D setup is created in the Ansys HFSS platform as per the CISPR-25 standard [7]. Inverter i.e. equipment under test [EUT] Pcb file in $\mathrm{ODB}++$ form is brought in a simulation platform and integrated with the test setup as shown in Fig 3 .

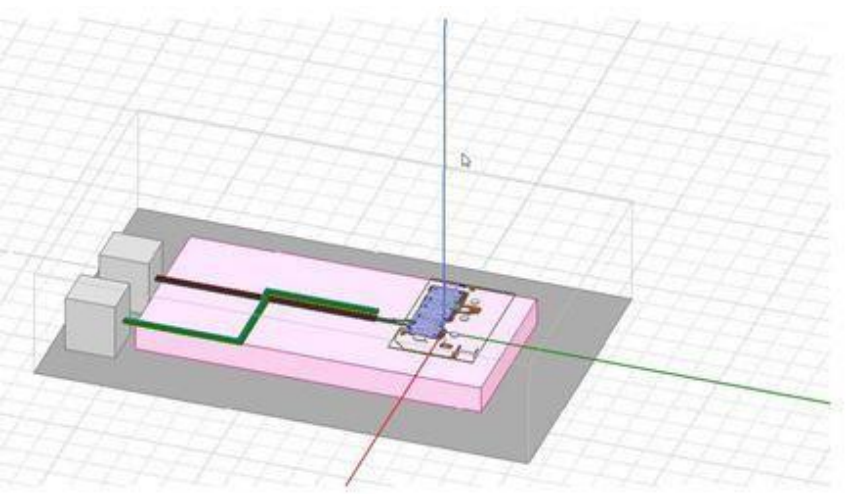

Fig 3. Conducted emission test set up

\section{Radiated emission setup}

Radiated emission setup is created according to CISPR-25 standard.3-D [7] antennas are simulated separately and integrated with a radiation emission test setup.

Monopole antenna is used to measure emission in the 0.15$30 \mathrm{MHz}$ frequency range as shown in Fig 4. and Biconical antenna is used to measure emission in $30-300 \mathrm{MHz}$ range as shown in Fig 5.

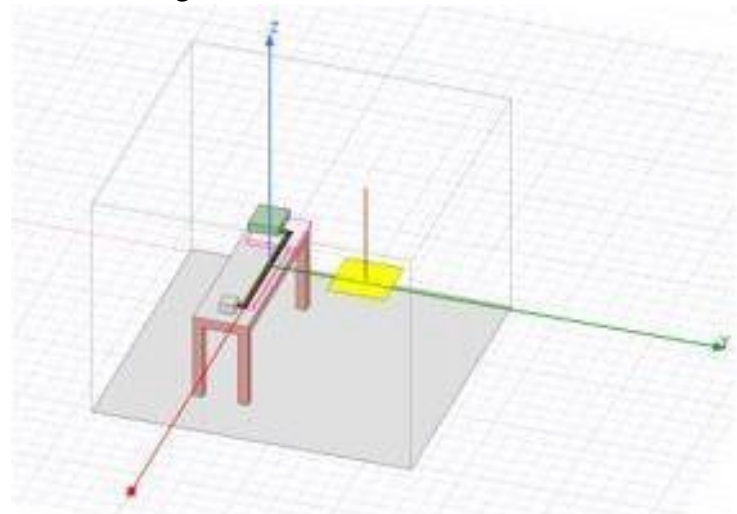

Fig 4. Radiated emission test setup with Monopole antenna

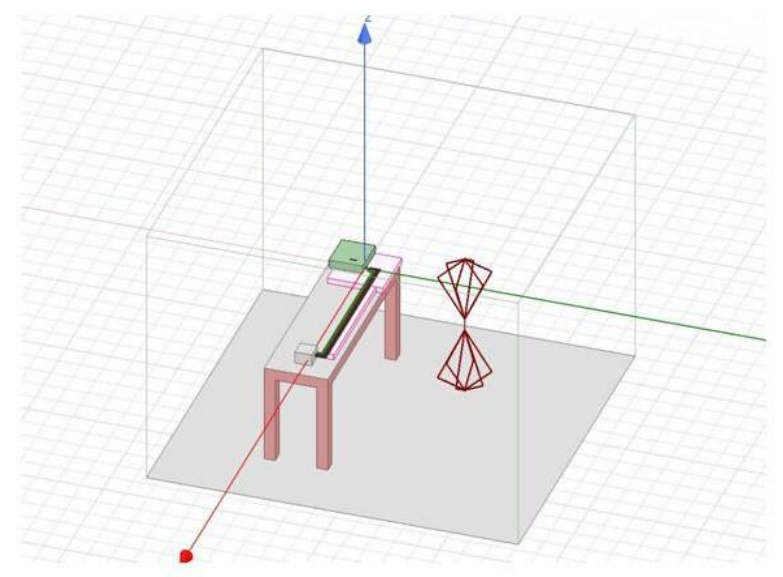

Fig 5. Radiated emission test setup with Biconical antenna

Simulation is also carried out by creating the radiation boundary around the EUT and radiated emission is measured at $360^{\circ}$ angle as shown in Fig 6 .

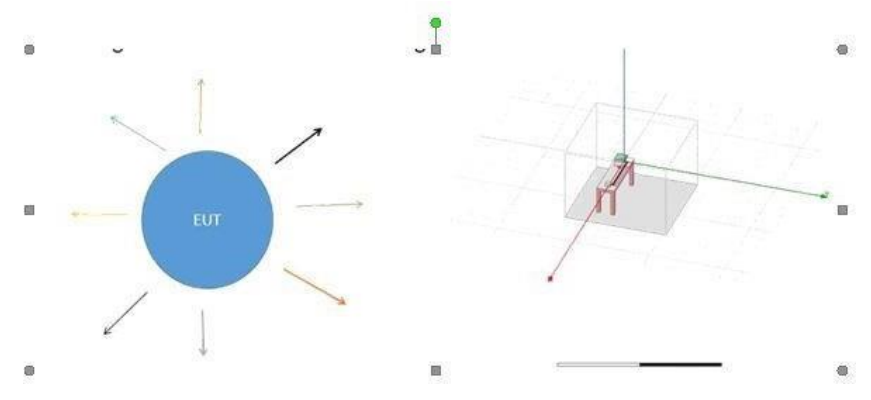

Fig 6. Radiated emission test setup with radiation boundary.

\section{RESULTS AND DISCUSSION}

The conducted emission is measured in $\mathrm{dB}$ for frequency range of $0.15-108 \mathrm{MHz}$ as shown in Fig.7. It is compared with class-3 limit of CISPR-25 standard. The emission is crossing the limit for $0.45-0.8 \mathrm{MHz}$ and it is within the limit for other frequency values. It is also observed the emission is fully compliant with CISPR 25 standard class 1 and 2. And the emission testing is failing for CISPR 25 Class 4 and 5 as they have more stringent limits. Red region in the class3 limit line indicates region where emissions are crossing the limit. 
International Journal of Engineering Applied Sciences and Technology, 2020

Vol. 5, Issue 3, ISSN No. 2455-2143, Pages 446-450

Published Online July 2020 in IJEAST (http://www.ijeast.com)

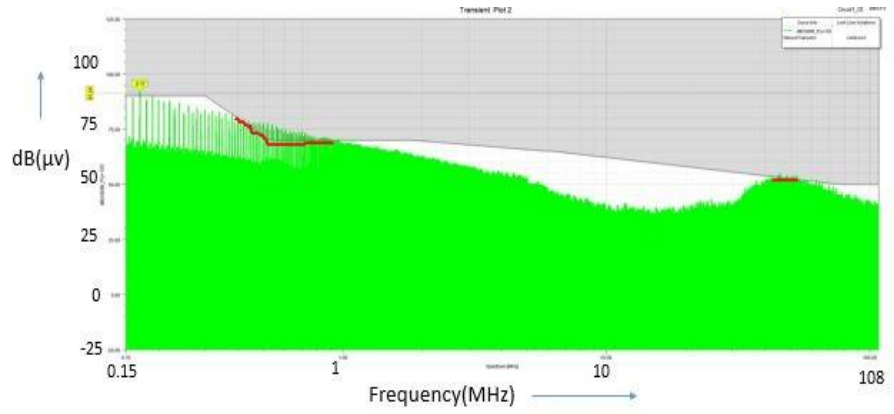

Fig.7. Conducted emission result

Radiated emission result for $0.15-30 \mathrm{MHz}$ measured using monopole antenna is as shown in Fig 8. Emission result is compared with class 1 limits of CISPR 25 standard and its is meeting class 1 . The result is partially complaint with class 2 limit and it is failing for class 3,4 and 5 .

To meet the CISPR 25 standard it is expected that emission results should be minimum within class 1 limit. As number of compliance with classes increase the product can withstand more vulnerable conditions.

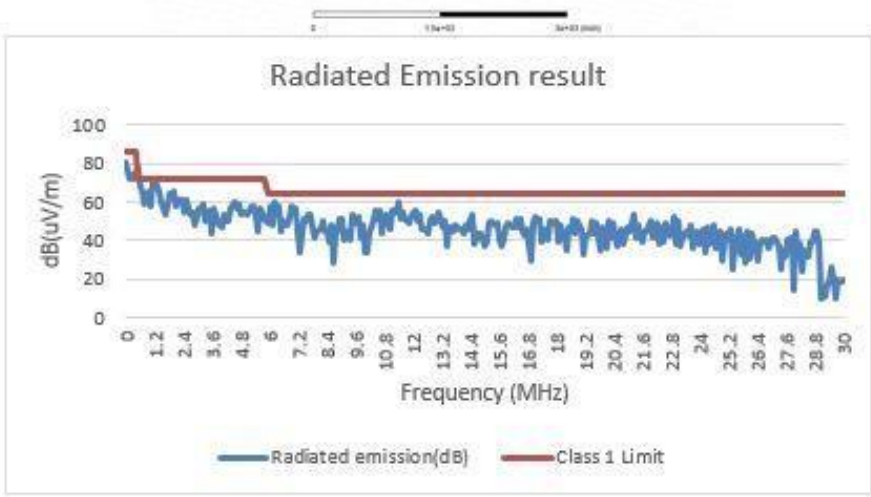

Fig 8. Radiated emission result with Monopole antenna for the $0.15-30 \mathrm{MHz}$ frequency range

Radiated emission result for the frequency range 30$300 \mathrm{MHz}$ measured using Biconical antenna is as shown in Fig 9 and is compared with the emission measured by creating radiation boundary. The emission is meeting class 1,2,3,4 and 5 limits of CISPR-25 standard. The usage of radiation boundary gives more accurate results since it captures emission in $360^{\circ}$ direction and plots the emission which is highest in that frequency.

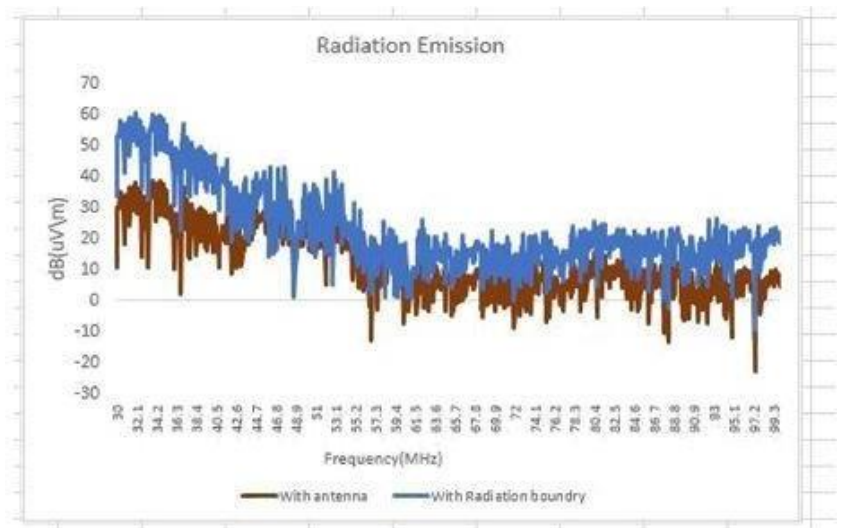

Fig 9. Comparison of radiated emission result with antenna and with radiation boundary for $30-300 \mathrm{MHz}$ frequency range

Hardware experimental setup involves radiation emission testing using monopole antenna in a closed anechoic chamber to measure emission for $0.15-30 \mathrm{Mhz}$ frequency range as per CISPR-25 Standard.

Experimental and simulation results simulation result are compared as shown in Fig 10. It can be observed that simulation result is matching experimental result. Ansys provides satisfactory results for emission testing.

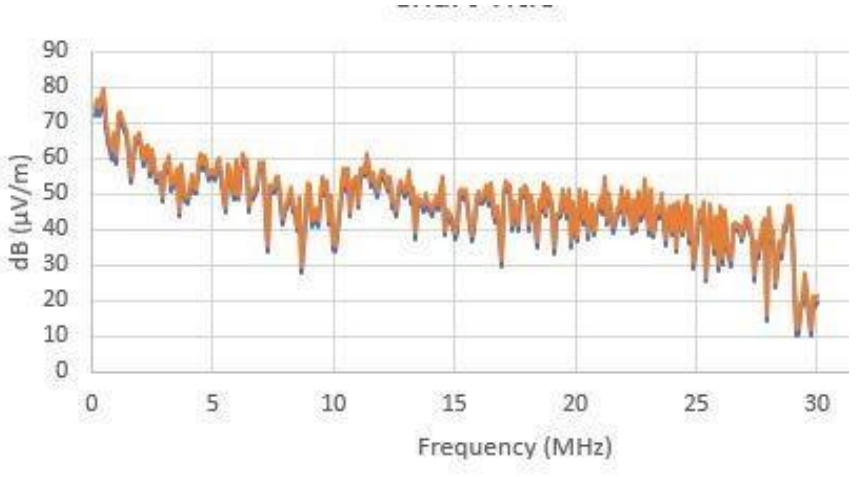

- Simulation result $\quad$ Experimental Result

Fig 10. 3-D simulation and experimental comparison of radiated emission with Monopole antenna for the 0.15$30 \mathrm{MHz}$ frequency range

This process of using 3-D simulation for emission measurement allows for correction in the PCB layout of EUT and scope for improvement if required $s$ the design phase itself.

\section{CONCLUSION}

EMC standards in automotive industries are very important with the rise in era of electric vehicles. Conducted and radiated emission testing is carried out as per CISPR- 25 standard and emissions measured are compared with the class limits. The results show the 
successful testing capabilities of the methodology used for EMC both for conducted and radiated emissions from the samples.

\section{FUTURE WORK}

EMC of the device can be analyzed with respect to emission and immunity through 3-D simulation.

\section{REFERENCES}

[1] J. W. W. EVERETT, "Electromagnetic Compatibility: A Position Paper," in IEEE Transctions on Electromagnetic Compatibility, 1966.

[2] F. M. a. K. J. Dejan Kos, "Conductive Emission in swithed -mode Power Converters," in IEEE Transctions on Electromagnetic Compatibility, 2005.

[3] L. ,. LEnsini, "Conducted Emissions on DC power grids," in International Symposium on Electromagnetic Compatibility, 2018.

[4] R. T. a. C. V. Mohammed Laour, "Modeling and Analysis of Conducted and Radiated emissions due to Common mode current of a Buck converter," in IEEE Transctions on Electromagnetic compatibility, 2017.

[5] F. Lafon, "Identification and study of influential Parameters in CISPR 25 Radiated emission test setup," in IEEE Tranctions on Electromagnetic Compatibility, 2016.

[6] M. B. S. T. ,. H. P. Hillenbrand, "Transient Cosimulation of Electromagnetic Emissions caused by a single Phase inverter," in International Symposium on Electromagnetic Compatibility, 2017.

[7] "Websore IEC," 2016. [Online]. Available: https://webstore.iec.ch. 